\title{
Impact of peroxisome proliferator-activated receptor $\gamma$ on angiotensin II type 1 receptor-mediated insulin sensitivity, vascular inflammation and atherogenesis in hypercholesterolemic mice
}

\author{
Vedat Tiyerili, Ulrich M. Becher, Bakary Camara, Cihan Yildirimtürk, Adem Aksoy, \\ Moritz Kebschull, Nikos Werner, Georg Nickenig, Cornelius Müller
}

Medizinische Klinik und Poliklinik II, Innere Medizin, Universitätsklinikum Bonn, Bonn, Germany

Submitted: 11 July 2013

Accepted: 14 August 2013

Arch Med Sci 2015; 11, 4: 877-885

DOI: 10.5114/aoms.2015.53309

Copyright $\odot 2015$ Termedia \& Banach

\section{Abstract}

Introduction: The angiotensin II type 1 receptor (AT1R) and the peroxisome proliferator-activated receptor $\gamma$ (PPAR $\gamma$ ) have been implicated in the pathogenesis of atherosclerosis. A number of studies have reported that AT1R inhibition or genetic AT1R disruption and PPAR $\gamma$ activation inhibit vascular inflammation and improve glucose and lipid metabolism, underscoring a molecular interaction of AT1R and PPAR $\gamma$. We here analyzed the hypothesis that vasculoprotective antiinflammatory and metabolic effects of AT1R inhibition are mediated by PPAR $\gamma$. Material and methods: Female $A \mathrm{ADE}^{-/-} / \mathrm{AT}_{1} \mathrm{R}^{-/}$mice were fedwith a high-fat and cholesterol-rich diet and received continuous treatment with the selective PPAR $\gamma$ antagonist GW9662 or vehicle at a rate of $700 \mathrm{ng} / \mathrm{kg} / \mathrm{min}$ for 4 weeks using subcutaneously implanted osmotic mini-pumps. Additionally, one group of female $\mathrm{ApoE}^{-1-}$ mice served as a control group. After treatment for 4 weeks mice were sacrificed and read-outs (plaque development, vascular inflammation and insulinsensitivity) were performed.

Results: Using AT1R deficient ApoE $E^{-/-}$mice (ApoE $E^{-/} / A T 1 R^{-/-}$mice) we found decreased cholesterol-induced endothelial dysfunction and atherogenesis compared to ApoE $\mathrm{E}^{-/-}$mice. Inhibition of PPAR $\gamma$ by application of the specific PPAR antagonist GW9662 significantly abolished the anti-atherogenic effects of AT1R deficiency in $\mathrm{ApoE}^{-/-} / \mathrm{AT} 1 \mathrm{R}^{-/-}$mice (plaque area as \% of control: $\mathrm{ApoE}^{-/-}$: 39

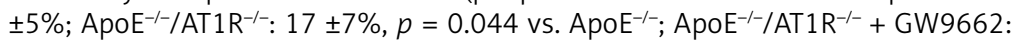
$31 \pm 8 \%, p=0.047 \mathrm{vs}$. Apo $\left.\mathrm{E}^{-/-} / \mathrm{AT}^{\mathrm{R}} \mathrm{R}^{-/}\right)$. Focusing on IL 6 as a pro-inflammatory humoral marker we detected significantly increased IL-6 levels in GW9662-treated animals (IL-6 in pg/ml: $\mathrm{ApoE}^{-/}: 230 \pm 16$; $\mathrm{ApoE}^{-/-} / \mathrm{AT}^{\mathrm{R}} \mathrm{R}^{-1-}: 117 \pm 20, p=0.01 \mathrm{vs}$. $\mathrm{ApoE}^{-/}$; $\mathrm{ApoE}^{-/-} / \mathrm{AT}_{1 \mathrm{R}^{-/-}}+\mathrm{GW} 9662: 199 \pm 20, p=0.01 \mathrm{vs}$. ApoE $^{-/-} / \mathrm{AT}^{\mathrm{R}^{-/-}}$), while the anti-inflammatory marker IL-10 was significantly reduced after PPAR $\gamma$ inhibition in GW9662 animals (IL-10 in pg/ml: ApoE ${ }^{-/}: 18 \pm 4$; $\mathrm{ApoE}^{-/-} / \mathrm{AT}^{\mathrm{R}} \mathrm{R}^{-/-}: 55 \pm 12$,

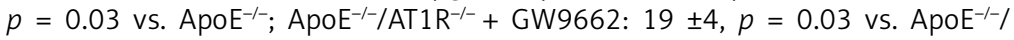
AT1 $\mathrm{R}^{-/}$). Metabolic parameters of glucose homeostasis (glucose and insulin tolerance test) were significantly deteriorated in $\mathrm{ApoE}^{-/-} / \mathrm{AT} 1 \mathrm{R}^{-/-}$mice treated with GW9662 as compared to vehicle-treated ApoE $E^{-/-} / A T 1 R^{-/-}$mice. Systolic blood pressure and plasma cholesterol levels were similar in all groups.

Conclusions: Genetic disruption of the AT1R attenuates atherosclerosis and improves endothelial function in an $\mathrm{ApoE}^{-/-}$mouse model of hypercholesterolemia-induced atherosclerosis via PPAR $\gamma$, indicating a significant role of PPAR $\gamma$ in reduced vascular inflammation, improvement of insulin sensitivity and atheroprotection of AT1R deficiency.

Key words: angiotensin II type 1 receptor, peroxisome proliferatoractivated receptor $\gamma$, inflammation, atherosclerosis, insulin sensitivity.

\author{
Corresponding author: \\ Vedat Tiyerili MD \\ Medizinische Klinik \\ und Poliklinik II \\ Universitätsklinikum Bonn \\ Sigmund-Freud-Str. 25 \\ 53105 Bonn, Germany \\ Phone: +49228 28715217 \\ Fax: +49 22828711271 \\ E-mail: Vedat.Tiyerili@ \\ ukb.uni-bonn.de
}




\section{Introduction}

The renin-angiotensin-aldosterone system (RAAS) and especially the angiotensin II type 1 receptor (AT1R) have been implicated in cardiovascular pathophysiology [1]. Most known effects of angiotensin II are mediated via activation of the AT1R $[1,2]$. Angiotensin II type 1 receptor activation is not only involved in vasoconstriction, salt homoeostasis and control of other neurohumoral systems, but also induces reactive oxygen species (ROS) production maintaining humoral and cellular inflammation [3, 4]. Clinically, selective angiotensin receptor blockers (ARBs) are widely used in the treatment of hypertension and hypertension-related end-organ damage [5]. In addition to their protective role in the cardiovascular system, ARBs have been recognized recently as regulators of glucose and lipid metabolism in adipocytes and adipose tissue. Moreover, AT1R blockade improved insulin sensitivity in animal models of insulin resistance [6]. Clinically inhibition of the RAAS by administration of ARBs exerts favorable metabolic effects that might prevent type 2 diabetes mellitus (T2DM) in high-risk individuals [7-10]. Mechanistically a number of studies have reported that AT1R blockers activate peroxisome proliferator-activated receptor $\gamma$ (PPAR $\gamma$ ) in vitro and in vivo [11, 12]. Peroxisome proliferator-activated receptor $\gamma$ is predominantly detected in adipose tissue, macrophages, vascular cells and intestine and plays an important role in the regulation of adipogenesis, insulin sensitivity and lipid metabolism [13, 14]. Furthermore, PPAR $\gamma$ activation has been associated with anti-atherosclerotic effects including reduced formation of ROS [15]. More recently, PPAR $\gamma$ has been shown to be involved in the downregulation of several inflammatory cytokines and inhibition of inflammation by reduced transcription of inflammatory response genes (such as IL-2, IL-6, IL-8, TNF- $\alpha$ and metalloproteases) negatively interfering with pro-inflammatory activation of $\mathrm{NF}-\kappa \mathrm{B}$, STAT and AP-1 signaling pathways $[16,17]$.

A number of in vitro studies have reported a reversed molecular regulation of AT1R and PPAR $\gamma$. In vitro studies investigating the interaction of PPAR $\gamma$ and the AT1R in vascular smooth muscle cells (VSMC) showed that activated PPAR $\gamma$ suppresses AT1R gene expression and vice versa, suggesting that pharmacological blockade or genetic disruption of the AT1R leads to enhanced PPAR $\gamma$ activity, thereby mediating anti-atherosclerotic effects in the vascular compartment $[15,16]$. However, the relevance of AT1R deficiency upon AT1R and PPAR $\gamma$ interaction has not been determined in an in vivo model of cholesterol-induced atherosclerosis.

In the present study we hypothesize that genetic disruption of the AT1R leads to improved atheroprotection by reduced vascular inflamma- tion and increased insulin sensitivity via PPAR $\gamma$. Our aim was to determine whether vasculoprotection of genetic AT1R deficiency was attenuated by selective pharmacological inhibition of PPAR $\gamma$.

\section{Material and methods}

\section{Animals and treatment protocol}

Female, 6-week-old homozygous apolipoprotein E deficient $\left(\mathrm{ApoE}^{-/-}\right)$mice (genetic background: C57BL/6J, Charles River, Sulzfeld, Germany) were crossed with AT1R- knock-out mice $\left(A T 1 R^{--}\right)$with an identical genetic background (kindly provided by Dr. Coffmann, University of North Carolina) until homozygous double-knockout (ApoE $\left.\mathrm{E}^{-/-} / \mathrm{AT}_{1} \mathrm{R}^{-/-}\right)$ mice were obtained. Female $A p o E^{-1-} / A_{T} 1 R^{-/-}$mice were fed with a high-fat and cholesterol-rich diet that contained $21 \%$ fat, $19.5 \%$ casein, and $1.25 \%$ cholesterol (Ssniff, Germany) and received a continuous treatment with the selective PPAR $\gamma$ antagonist GW9662 (Sigma-Aldrich) or vehicle at a rate of $700 \mathrm{ng} / \mathrm{kg} / \mathrm{min}$ for 4 weeks using subcutaneously implanted osmotic mini-pumps (Alzet, Germany). Additionally, one group of female $\mathrm{ApoE}^{-/-}$ mice served as the control group treated with vehicle through osmotic minipumps. All mice had unrestricted access to water and standard mouse chow and were maintained in a room with a 12hour light/dark cycle and a constant temperature of $22^{\circ} \mathrm{C}$. After treatment for 4 weeks mice were sacrificed and read-outs were performed. All animal experiments were performed in accordance with institutional guidelines and the German Animal Protection Law. The experimental setting is depicted as a flow chart in Figure 1.

\section{Measurements of metabolic parameters}

Systolic blood pressure (SBP), diastolic blood pressure and heart rate were measured by a computerized tail-cuff system (CODA 6, Kent Scientific) in conscious animals. Mice were trained for 3 consecutive days in the pre-warmed tail-cuff device to accustom them to the procedure, followed by additional measurements of SBP and heart rate on 3 consecutive days. On each day of blood pressure determination, 20 measurements were obtained and averaged for each individual animal. The mean values of all 3 days were used for comparisons. Blood glucose levels were measured using Accu-Chek-Sensor (Roche, Mannheim, Germany). Plasma cholesterol concentrations were determined by gas-liquid chromatography-mass spectrometry. Blood samples were collected by tail vein puncture. Body weights were measured weekly.

\section{Glucose and insulin tolerance test}

To determine blood glucose tolerance, an intraperitoneal glucose tolerance test (ipGTT) was ex- 


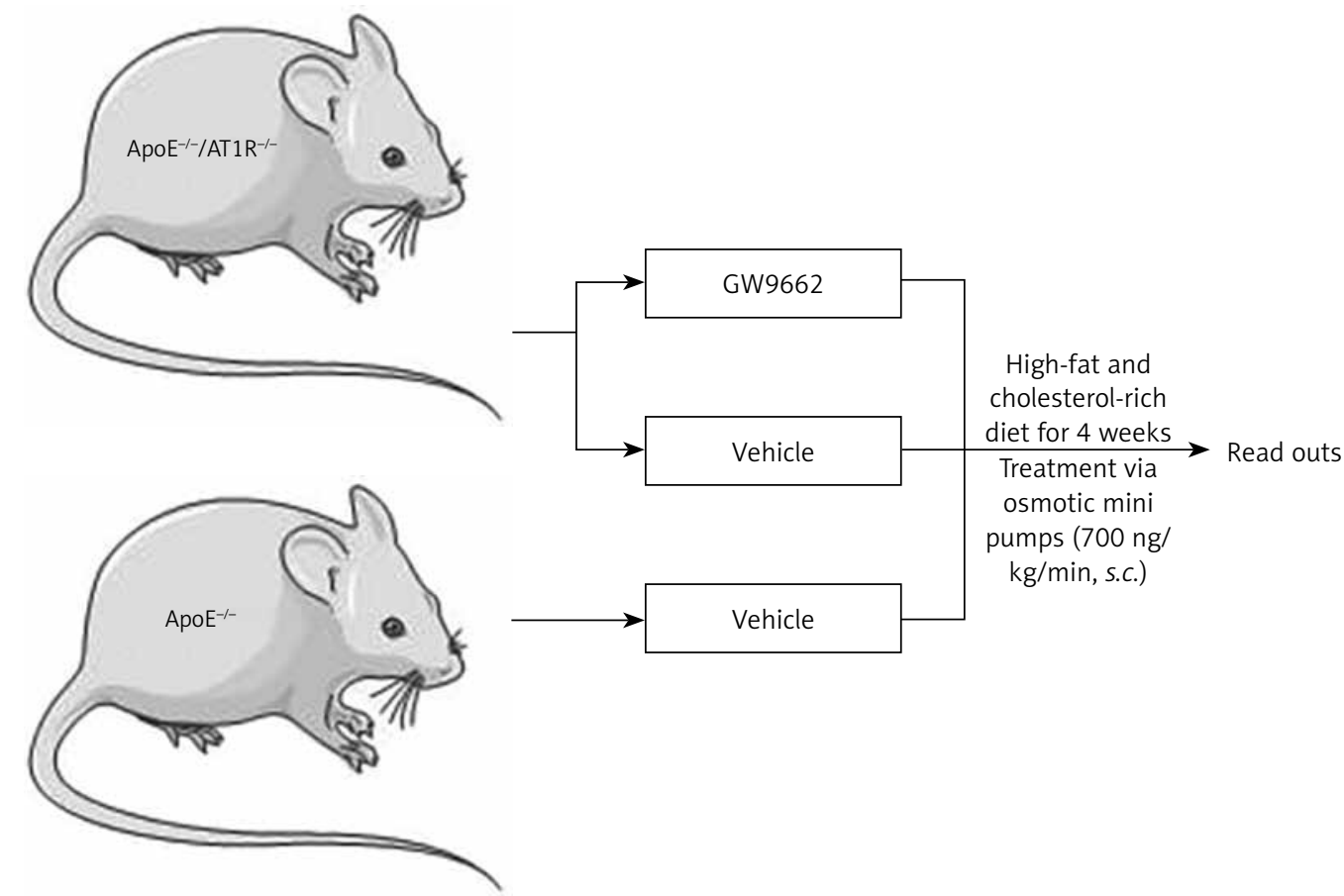

Figure 1. Experimental setting. Female $\mathrm{ApoE}^{-/-} / \mathrm{AT}_{1 \mathrm{R}^{-/-}}$mice were fed with a high-fat and cholesterol-rich diet and received continuous treatment with the selective PPAR $\gamma$ antagonist GW9662 or vehicle at a rate of $700 \mathrm{ng} / \mathrm{kg} / \mathrm{min}$ for 4 weeks using subcutaneously implanted osmotic mini-pumps. Additionally, one group of female ApoE ${ }^{-/-} \mathrm{mice}^{-}$ served as a control group and was treated with vehicle through implanted osmotic minipumps. After treatment for 4 weeks mice were sacrificed and read-outs were performed

ecuted. Mice were refrained from eating for $18 \mathrm{~h}$ and given glucose (G 20 Glucose solution, B. Braun) adjusted to their body weight ( $2 \mathrm{~g} / \mathrm{kg}$ body weight) by intraperitoneal injection. Blood glucose readings (Accu-Chek-Sensor, Roche, Mannheim, Germany) were taken at baseline and after 15, 30 and $45 \mathrm{~min}$. In addition, an intraperitoneal insulin tolerance test (ipITT) was executed after $6 \mathrm{~h}$ fasting. Here, the animals were injected with human insulin (Actrapid; Novo-Nordisk; $0.75 \mathrm{U} / \mathrm{kg}$ body weight) intraperitoneally.

\section{Aortic ring preparations and tension recording}

After excision of the descending aorta, the vessel was immersed in chilled, modified Tyrode buffer containing, in mmol/l, $\mathrm{NaCl} 118.0, \mathrm{CaCl}_{2}$ 2.5, $\mathrm{KCl}$ 4.73, $\mathrm{MgCl}_{2}$ 1.2, $\mathrm{KH}_{2} \mathrm{PO}_{4}$ 1.2, $\mathrm{NaHCO}_{3}$ 25.0, Na EDTA 0.026, D(+)glucose 5.5, pH 7.4. Three-millimeter rings were mounted in organ baths filled with the above-described buffer $\left(37^{\circ} \mathrm{C}\right.$; continuously aerated with $95 \% \mathrm{O}_{2}$ and $\left.5 \% \mathrm{CO}_{2}\right)$ and were attached to a force transducer, and isometric tension was recorded. The vessel segments were gradually stretched over $60 \mathrm{~min}$ to a resting tension of $10 \mathrm{mN}$. Drugs were added in increasing concentrations in order to obtain cumulative concentration-response curves: $\mathrm{KCl} 20$ and $40 \mathrm{mmol} / \mathrm{l}$, angiotensin II $1 \mathrm{nmol} / \mathrm{l}$ to $1 \mathrm{\mu mol} / \mathrm{l}$, phenylephrine
$1 \mathrm{nmol} / \mathrm{l}$ to $10 \mu \mathrm{mol} / \mathrm{l}$, carbachol $10 \mathrm{nmol} / \mathrm{l}$ to 100 $\mu \mathrm{mol} / \mathrm{l}$, and nitroglycerin $1 \mathrm{nmol} / \mathrm{l}$ to $10 \mu \mathrm{mol} / \mathrm{l}$. The drug concentration was increased when vasoconstriction or relaxation was completed. Drugs were washed out before the next substance was added.

\section{Staining of atherosclerotic lesions and morphometric analysis}

Hearts with ascending aortas were embedded in Tissue Tek OCT embedding medium and sectioned on a Leica cryostat $(9 \mu \mathrm{m})$, starting at the apex and progressing through the aortic valve area into the ascending aorta and the aortic arch and placed on poly-L-lysine (Sigma) coated slides. At least 15 consecutive sections per animal were used for analysis. For detection of atherosclerotic lesions, aortic cryosections were fixed with 3.7\% formaldehyde and stained with oil red 0 working solution. For morphometric analysis, hematoxylin staining was performed according to standard protocols. Stained samples were examined with a Zeiss Axiovert 200 microscope (Carl Zeiss Jena, Germany) and an AxioCam MRc5. Images were acquired with Zeiss AxioVision software Rel. 4.5.0 and processed with Corel Graphic Suite X4. For quantification of atherosclerotic plaque formation in the aortic root, lipid staining area and total area of serial histological sections were measured. Ath- 
erosclerosis data are expressed as lipid-staining area in percent of total surface area. The investigator who performed the histological analyses was unaware of the hypothesis of this study and the treatment of the respective animal group.

\section{Immunohistochemical analysis of the monocyte/macrophage marker MOMA-2}

For immunohistochemical analysis, cryosections were assessed for the monocyte/macrophage marker MOMA-2 with an indirect immunoenzymatic method. The primary antibody (monoclonal rat anti-mouse MOMA-2 antibody, Acris) was applied for $1 \mathrm{~h}$ at room temperature and thereafter at $4^{\circ} \mathrm{C}$ overnight. Slides were then incubated with an alkaline phosphatase-conjugated-secondary-antibody (goat anti-rat IgG, Sigma) for $1 \mathrm{~h}$ at room temperature. Color reaction was accomplished with FastRed (Sigma). Nuclei were counterstained with hematoxylin. Isotype-specific antibodies were used for negative controls. Monocyte recruitment was quantified by expression of MOMA-2 positive staining area in percent of total aortic plaque size estimated by an average of 5 sections from each animal. Sections were examined under a Zeiss Axiovert.

\section{Measurements of cytokines}

Plasma IL-6 and IL-10 were determined using an ELISA kit specific for mouse (Sabioscience, a Qiagen company, Germany). Samples and 2\% bovine serum albumin buffer were transferred to wells pre-coated with antibodies and were incubated for $120 \mathrm{~min}$ at room temperature. Detection antibodies (1: 20 dilutions) were added for $60 \mathrm{~min}$ at $37^{\circ} \mathrm{C}$. Immunodetection was accomplished using Avidin-HRP (1 : 1000 dilutions, incubation time 30 min in dark) and a development solution. The absorbance was read at $570 \mathrm{~nm}$ with $450 \mathrm{~nm}$ as the reference wavelength using a photometer (Tecan Austria, Austria).

\section{Statistical analysis}

Data are presented as mean \pm SEM. Statistical analysis was performed using the ANOVA test followed by the Neuman-Keuls post hoc analysis. Value of $p<0.05$ indicates statistical significance.

\section{Results}

\section{Blood pressure, heart rate and metabolic parameters}

Mice were treated as described in the method section and depicted in Figure 1. Body weight was identical in all groups before treatment and slightly but equally increased during the 4 weeks of cholesterol-rich diet. Systolic and diastolic blood pressure, as assessed by the computerized tailcuff method, remained unchanged before and after treatment. After 4 weeks no significant differences were determined in total cholesterol levels and fasting blood glucose levels. All parameters are shown in Table I. In contrast to vehicle-treated $\mathrm{ApoE}^{-/-} / \mathrm{AT}_{1} \mathrm{R}^{-/-}$mice, the glucose tolerance test was significantly impaired in vehicle-treated ApoE ${ }^{-/-}$mice (Figure $2 \mathrm{~A}$ ). Consistently, significant impaired insulin utilization was detected in vehicle-treated ApoE ${ }^{-/-}$mice (Figure $2 \mathrm{~B}$ ). The positive effect of AT1R-deficiency in $\mathrm{ApoE}^{-/-}$mice on glucose homeostasis was abolished in GW9662-treated $\mathrm{ApoE}^{-/-} / \mathrm{AT}_{1 \mathrm{R}^{-/}}$mice (Figures $2 \mathrm{~A}, \mathrm{~B}$ ).

\section{Endothelial function}

Sections of the ascending aorta were used to determine endothelial function in organ chamber experiments. Endothelium-dependent vasodilatation was significantly impaired in vehicle-treated ApoE ${ }^{-/-}$mice. AT1R deficiency attenuates endothelial dysfunction in $\mathrm{ApoE}^{-/-}$mice, whereas PPAR $\gamma$ inhibition by GW9662 decreased endothelium-dependent vasodilatation in $\mathrm{ApoE}^{-/-} / \mathrm{AT}_{1 \mathrm{R}^{-/-}}$mice. Endothelium independent vasorelaxation induced by nitroglycerin was similar in all groups (data not shown). In addition, vasoconstriction induced by phenylephrine or KCL was similar in all groups (data not shown).

\section{Atherosclerotic lesion formation}

Development of atherosclerotic lesions was analyzed using oil red $O$ staining and macroscopic analysis of the aortic root. Figure $3 \mathrm{~B}$ shows representative aortic root preparations of the different groups of animals. In contrast to vehicle-treated $\mathrm{ApoE}^{-/-}$mice fed a high-cholesterol diet for 4 weeks, vehicle-treated $A p o E^{-/-} / A_{T} 1 R^{-/-}$mice do

Table I. Blood pressure, heart rate and metabolic parameters

\begin{tabular}{|lccccc|}
\hline Parameter & $\begin{array}{c}\text { Total cholesterol } \\
{[\mathrm{mg} / \mathrm{dl}]}\end{array}$ & $\begin{array}{c}\text { Fasting blood } \\
\text { glucose }[\mathrm{mg} / \mathrm{dl}]\end{array}$ & Body weight [g] & $\begin{array}{c}\text { Systolic BP } \\
{[\mathrm{mm} \text { Hg] }}\end{array}$ & $\begin{array}{c}\text { Heart rate } \\
{[\mathrm{beats} / \mathrm{min}]}\end{array}$ \\
\hline ApoE $^{-/-}$ & $1321 \pm 96$ & $121 \pm 6$ & $26 \pm 8$ & $122 \pm 7$ & $816 \pm 34$ \\
\hline ApoE/AT1 ${ }^{-/-}$ & $1192 \pm 96$ & $109 \pm 12$ & $27 \pm 1$ & $133 \pm 4$ & $856 \pm 54$ \\
\hline ApoE/AT1 ${ }^{-/}+$GW9662 & $1279 \pm 82$ & $114 \pm 3$ & $25 \pm 2$ & $122 \pm 5$ & $898 \pm 46$ \\
\hline
\end{tabular}

To determine relevant cardiovascular effects, systolic BP, heart rate, fasting blood glucose levels, body weight and total cholesterol levels were assessed in all groups, $n=4-5$ per group. 
A

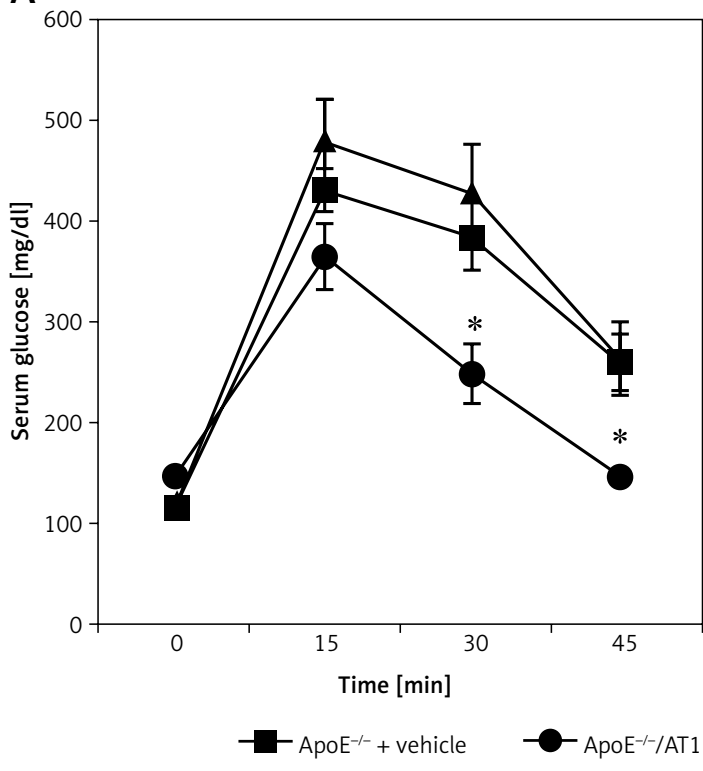

B

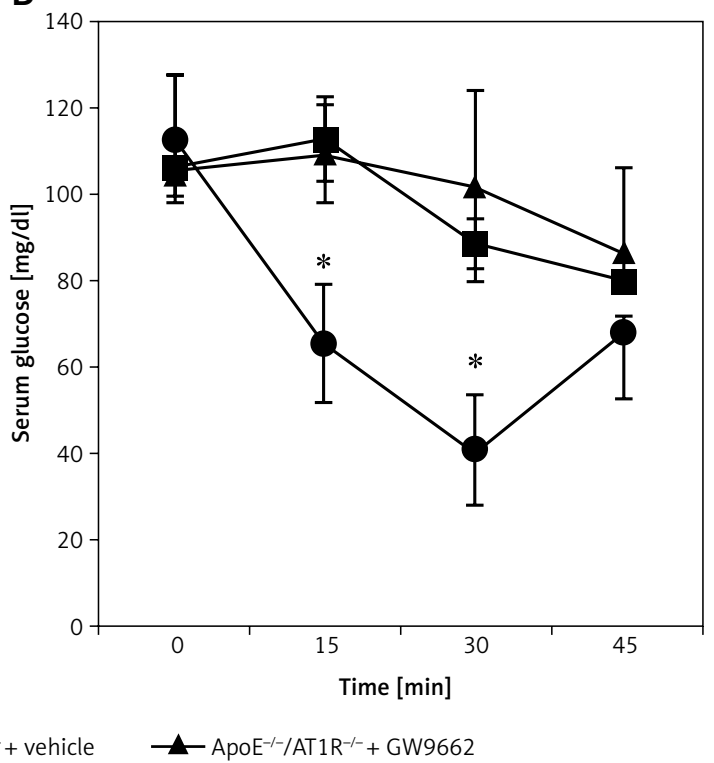

Figure 2. Insulin sensitivity. Intraperitoneal glucose (A) and insulin tolerance tests (B) (ipGTT and ipITT) were conducted after treatment with the selective PPAR $\gamma$ antagonist GW9662 or vehicle in ApoE ${ }^{-/-} / A T 1 R^{-/-}$mice that were concomitantly fed a high-fat, cholesterol-rich diet for 4 weeks. The positive effect of AT1R deficiency in ApoE ${ }^{-/-}$ mice on glucose homeostasis was abolished in GW9662-treated ApoE $E^{-/-} / A_{T} 1 R^{-/-}$mice (ipGTT (A): ApoE $E^{-/-} / A T 1 R^{-/-}+$ vehicle vs. ApoE ${ }^{-/-}+$vehicle, ${ }^{*} p=0.01, \mathrm{ApoE}^{-/-} / \mathrm{AT} \mathrm{R}^{-/-}+$vehicle vs. ApoE $\mathrm{E}^{-/-} / \mathrm{AT} 1 \mathrm{R}^{-/-}+\mathrm{GW} 9662,{ }^{*} p=0.01$, iplTT (A):

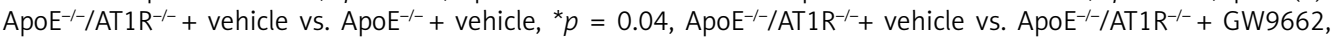
$\left.{ }^{*} p=0.04\right)$. Mean $\pm \mathrm{SEM}, n=4-5$ per group

not develop severe atherosclerotic lesion formation $\left(\mathrm{ApoE}^{-/-}+\right.$vehicle: $39.6 \pm 0.5 \%$ of total area vs. $\mathrm{ApoE}^{-/-} / \mathrm{AT}_{1 \mathrm{R}^{-/}}+$vehicle: $14 \pm 0.4 \%$ of total area, $p=0.044$, Figure $3 \mathrm{~B}$ ). The profoundly inhibited atherogenesis in vehicle-treated $\mathrm{ApoE}^{-/-} / \mathrm{AT}^{-/-}$ mice was substantially reduced by application of GW9662 (ApoE ${ }^{-/-} / \mathrm{AT}^{-/-}+$GW9662: $31 \pm 0.7 \%$ of total area vs. ApoE $E^{-/-} / A_{1} 1 R^{-/-}$vehicle: $14 \pm 0.4 \%$ of total area, $p=0.047$, Figure $3 \mathrm{~B}$ ). Quantitative analysis of atherosclerotic lesion formation is shown in Figure $3 \mathrm{C}$.

\section{Monocyte recruitment of atherosclerotic lesions and vascular inflammation}

For immunohistochemical analysis, cryosections were assessed for the monocyte/macrophage marker MOMA-2 with an indirect immunoenzymatic method. Figure 4 A shows representative aortic root preparations of animal groups and Figure $4 \mathrm{~B}$ quantification of monocyte recruitment in percent. In contrast to vehicle-treated $\mathrm{ApoE}^{-1-}$ / $\mathrm{AT}^{-1-}$ mice, GW9662-treated animals showed a non-significant tendency towards more monocyte recruitment in the atherosclerotic lesion of the aortic root $\left(\mathrm{ApoE}^{-/-} / \mathrm{AT}^{-/-}+\mathrm{GW} 9662: 2.1 \pm 0.8 \%\right.$ of total area vs. ApoE $\mathrm{E}^{-/-} / \mathrm{AT}_{1 \mathrm{R}^{-/-}}+$vehicle: $1.8 \pm 0.6 \%$ of total area, n.s.). Parameters of humoral pro-inflammation (IL-6) were significantly increased in GW9662-treated $\mathrm{ApoE}^{-/-} / \mathrm{AT}^{-/-}$mice $\left(\mathrm{ApoE}^{-/-} /\right.$ AT1 ${ }^{-1-}+$ GW9662: $199.5 \pm 20.5$ pg/ml vs. $\mathrm{ApoE}^{-/-}$ AT1 $\mathrm{R}^{-/-}+$vehicle: $117.1 \pm 19.2 \mathrm{pg} / \mathrm{ml}, p=0.01$
Figure $4 \mathrm{C}$ ), while the anti-inflammatory marker IL10 (ApoE ${ }^{-/-} / \mathrm{AT}^{-/-}+\mathrm{GW} 9662: 18.8 \pm 3.9 \mathrm{pg} / \mathrm{ml}$ vs. $A p o E^{-/-} / A T 1 R^{-/-}$+ vehicle: $55.2 \pm 12.3 \mathrm{pg} / \mathrm{ml}$, $p=0.03$, Figure $4 \mathrm{D}$ ) was significantly reduced after PPAR $\gamma$ inhibition.

\section{Discussion}

Cardiovascular disease (CVD) is the major cause of death in the western world [18]. The underlying biological mechanisms are complex and only insufficiently understood. The pathogenesis of atherosclerosis involves prolonged exposure to risk factors and a poorly understood genetic predisposition [19]. Oxidative stress and inflammation are decisively involved in the initiation and progression of atherosclerosis, leading to enhanced attraction, adhesion, and invasion of macrophages and lymphocytes, deposition of lipids within the vessel wall and plaque formation [20-22].

Activation of the AT1R is associated with many molecular and cellular events, such as increase of reactive oxygen species release and increased expression of pathophysiologically important genes, such as adhesion molecules, chemotaxis factors and proinflammatory cytokines [23]. In addition to molecular and cellular events, activation of the RAAS has a major impact on metabolic changes. Several newer signaling concepts with implications for cardiovascular physiology have emerged recently, adding substantial complexity to the physiological effects of receptor crosstalk in tar- 
A

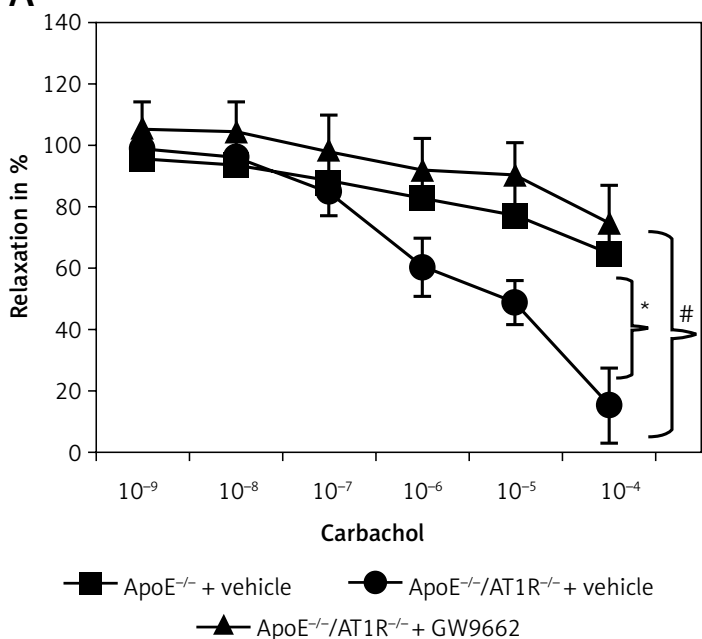

C

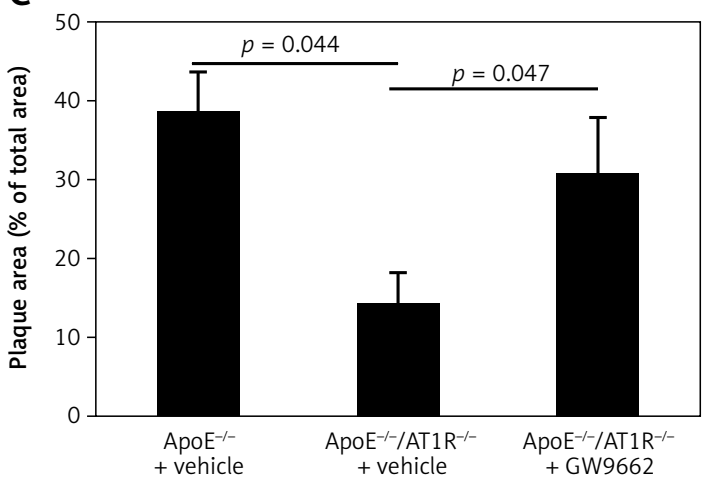

B
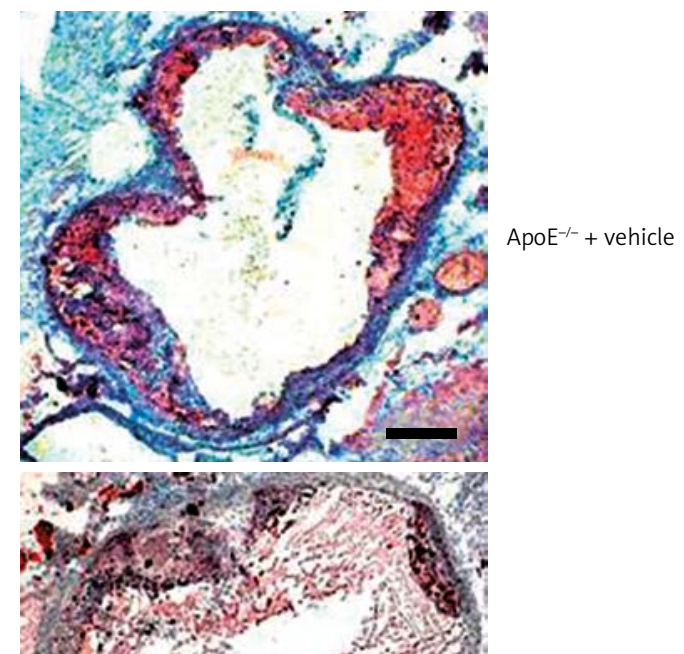

ApoE $E^{-/-} / A T 1 R^{-1}$ + vehicle

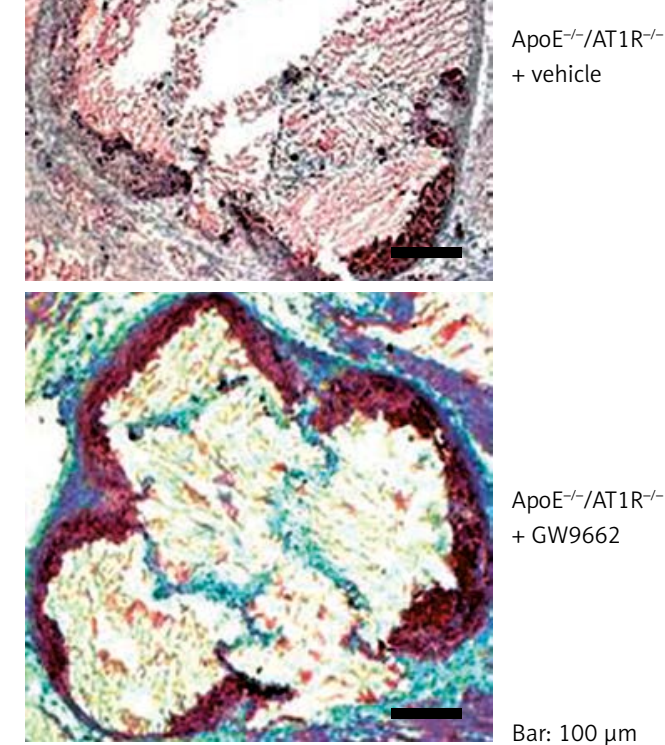

Figure 3. Endothelial function and atherosclerotic lesion formation. After 4 weeks aortic segments of vehicle-treated $\mathrm{ApoE}^{-/-}$- and vehicle- and GW9662-treated $\mathrm{ApoE}^{-/ /} \mathrm{AT}_{1} \mathrm{R}^{-/-}$mice were isolated and their functional performance was assessed in organ chamber experiments. Endothelium-dependent vasodilation induced by carbachol is shown in Figure $3 \mathrm{~A}$. Vehicle-treated $\mathrm{ApoE}^{-/-}$mice displayed severe impairment of endothelial function compared to vehicle-treated ApoE $\mathrm{E}^{-/-} / \mathrm{AT}_{1} \mathrm{R}^{-/-}$mice. Treatment of ApoE $\mathrm{E}^{-/ /} / \mathrm{AT}^{-1 \mathrm{R}^{-/-}}$mice with GW9662 antagonized the protective vas-

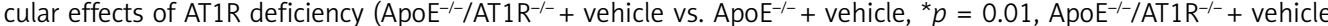
vs. ApoE $\left.\mathrm{E}^{-/-} / \mathrm{AT}_{1 R^{-/-}}+\mathrm{GW} 9662,{ }^{*} p=0.01\right)$. Vehicle-treated $\mathrm{ApoE}^{-/-}$mice displayed increased atherosclerotic lesion formation. AT1R deficiency in $\mathrm{Apo}^{-/-}$mice resulted in a significantly reduced area of atherosclerotic lesions, whereas GW9662 antagonized the atheroprotective effects of AT1R deficiency. Representative histological cross-sections of the aortic root were stained with oil red $\mathrm{O}$ to analyze atherosclerotic plaque development. B - Quantitative analysis of atherosclerotic lesion formation indicated as plaque area in \% of total area is depicted in Figure $3 \mathrm{C}^{-\mathrm{ApoE}^{-1-} /}$

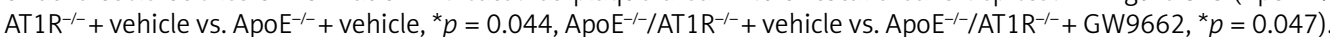
Mean \pm SEM, $n=4-5$ per group

get tissues [24, 25]. One concept posits that AT1R inhibition or deficiency upregulates PPAR $\gamma$, which also governs molecular, cellular and metabolic pathways directly relevant to CVD $[11,12,15]$.

The present study was undertaken to test the hypothesis that PPAR $\gamma$ mediates atheroprotection in AT1R-deficient animals via its anti-inflammatory and beneficial metabolic actions. We and others have shown previously that genetic disruption of the AT1R or AT1R inhibition by ARBs leads to inhibition of vascular oxidative stress, inflammation and atherogenesis $[14,26]$. However, the relevance of PPAR $\gamma$ in AT1R-deficiency mediated vascular protection has not been analyzed in a mouse model of genetic AT1R deficiency so far.

Here we show that PPAR $\gamma$ inhibition using a pharmacological approach abolished anti-atherogenic effects of genetic AT1R deficiency, leading to increased endothelial dysfunction and accelerated atherosclerosis in hypercholesterolemic 
A

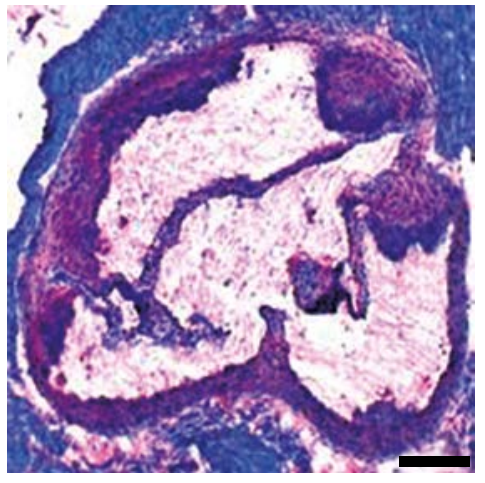

$\mathrm{ApoE}^{-/-}+$vehicle

B

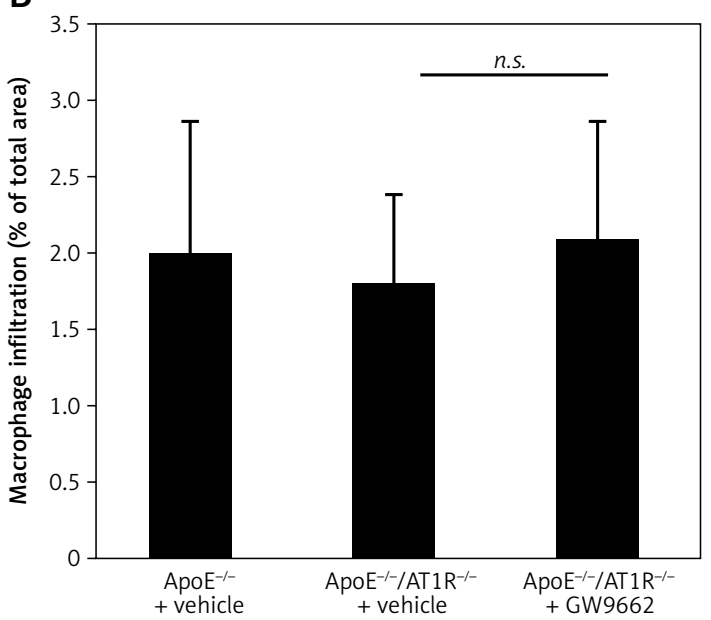

D

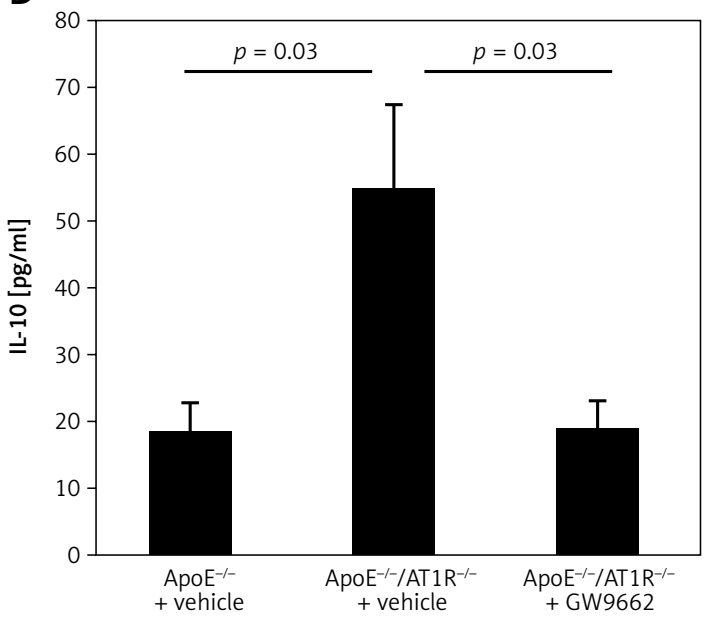

$\mathrm{ApoE}^{-/-}$mice. In addition, we show that the anti-inflammatory effects of AT1R deficiency are, at least in part, mediated via PPAR in vivo. Systemic PPAR $\gamma$ inhibition by GW9662 treatment of $\mathrm{ApoE}^{-/-}$ AT1 $\mathrm{R}^{-/-}$mice resulted in decreased transcription of the anti-inflammatory IL-10 gene and increased

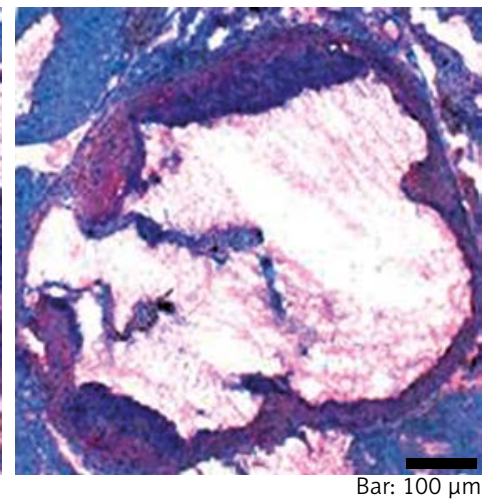

ApoE $\mathrm{E}^{-/-} / \mathrm{AT}^{-1 \mathrm{R}^{-/-}}+\mathrm{GW} 9662$

C

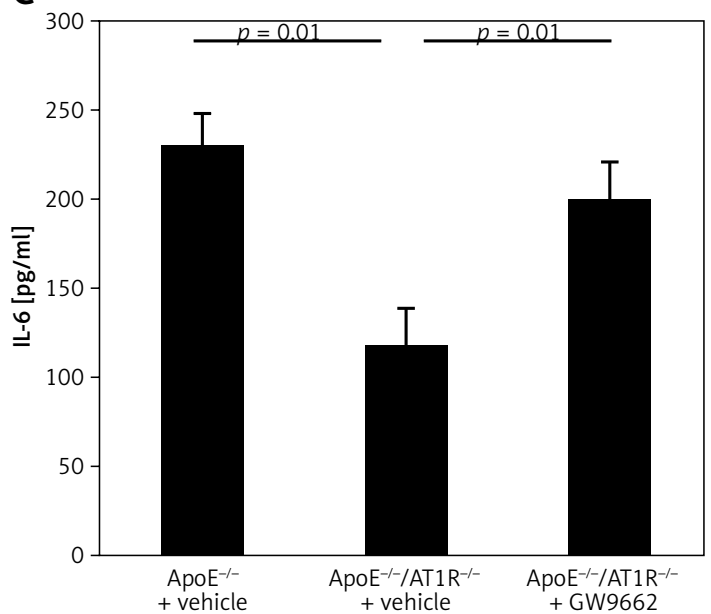

Figure 4. Monocyte recruitment and vascular inflammation. For immunohistochemical analysis, cryosections were assessed for the monocyte/ macrophage marker MOMA-2 with an indirect immunoenzymatic method. Figure $4 \mathrm{~A}$ shows representative aortic root preparations of MOMA-2 staining from all animal groups and Figure 4 B shows quantification of monocyte recruitment in percent. In contrast to vehicle-treated $\mathrm{ApoE}^{-/-} / \mathrm{AT}_{1} \mathrm{R}^{-/-}$mice, monocyte content in atherosclerotic plaques had a tendency to more monocyte recruitment in GW9662-treated animals. Plasma IL-6 (C) and IL-10 levels (D) were determined using an ELISA kit specific for mouse. The pro-inflammatory marker IL-6 was significantly increased in GW9662-treated animals

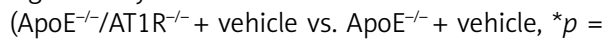
0.01, ApoE $\mathrm{E}^{-/-} / \mathrm{AT}_{1} \mathrm{R}^{-/-}$+ vehicle vs. ApoE $\mathrm{E}^{-/-} / \mathrm{AT}_{1} \mathrm{R}^{-/-}+$ GW9662, ${ }^{*} p=0.01$ ), while the anti-inflammatory marker IL-10 was significantly reduced after PPAR $\gamma$ inhibition (ApoE $E^{-/-} / A_{T} 1 R^{-1-}+$ vehicle vs. ApoE $E^{-/-}+$vehicle, ${ }^{*} p=0.03, \mathrm{ApoE}^{-/-} / \mathrm{AT}_{1} \mathrm{R}^{-/-}+$vehicle vs. ApoE ${ }^{-/-} /$ $\left.\mathrm{AT} \mathrm{R}^{-/-}+\mathrm{GW} 9662,{ }^{*} p=0.03\right)$. Mean $\pm \mathrm{SEM}, n=4-5$ per group

transcription of the pro-inflammatory IL-6 gene, thus favoring inflammation and deterioration of vascular function and morphology.

In addition to the influence on the inflammatory state by genetic perturbations of IL- 6 and IL-10, PPAR inhibition by GW9662 caused metabolic 
changes of glucose metabolism leading to insulin resistance, which maintains increased cardiovascular risk by promoting endothelial dysfunction and atherogenesis. Thus our data support the notion that inhibition of PPAR $\gamma$ in AT1R-deficient animals revealed multifactorial deterioration of parameters relevant for vascular homeostasis. Takeda et al. investigated this issue in vascular smooth muscle cells and reported downregulation of AT1R expression at the transcriptional level following stimulation of PPAR $\gamma$ [27]. Regarding vascular inflammation, Ji et al. [28] found that PPAR $\gamma$ agonist treatment of vascular cells in vitro and in vivo significantly reduced pro-inflammatory effects of Ang II. The modulatory effects of PPAR $\gamma$ were related to diminished activation of the pro-inflammatory toll-like receptor 4 (TLR4). TLR4 in turn has been attributed with consecutive activation of the IP10/PKC/NF- $\kappa B$ pathway. Many stimuli associated with the development of vascular disease, including Ang II activation AT1R, are capable of inducing pro-inflammatory transcriptional factors such as IL-6 [29].

Once activated, the transcription factor NF- $\kappa B$ binds to recognition elements in the promoter region of other pro-inflammatory genes and they act as dominant regulators of transcription of these genes to maintain inflammation [30]. In contrast, PPAR $\gamma$ and its agonists have been recognized as cardiovascular protective transcription factors. In many studies, the protective role of PPAR $\gamma$ in the pathogenesis of inflammatory diseases has been shown to be partly mediated through an NF- $\mathrm{KB}$ inhibition and IL-10-dependent mechanism [3134]. The present study demonstrates that antiinflammatory gene regulation of decreased IL-6 and increased IL-10 gene transcription in AT1R deficiency was significantly reversed after PPAR $\gamma$ inhibition within the vascular compartment, thereby abolishing atheroprotective properties of AT1R deficiency. However, the here demonstrated ability of GW9662 to inhibit PPAR $\gamma$-mediated effects of AT1R deficiency does not rule out occurrence of a mechanism independent of PPAR $\gamma$ inhibition, although GW9662 has not been associated with pleiotropic pharmacological effects independent of PPAR $\gamma$ inhibition.

Clinical observations in patients with metabolic syndrome defined by the coincidence of arterial hypertension and impaired glucose homeostasis treated with ARBs have revealed cardiovascular, cerebral, and renal protective effects beyond blood pressure control [35-37]. In addition to direct end-organ protection, pleiotropic effects have been suggested to be mediated by PPAR $\gamma$ agonism, thereby improving abnormalities of glucose and lipid metabolism, resulting in an anti-atherosclerotic effect in patients with hypertension and type 2 diabetes [10]. In several clinical trials, the effects of a certain subgroup of ARBs such as telmisartan on inflammation, glucose and lipid metabolism have been demonstrated, emphasizing the hypothesis of underlying molecular receptor interactions preventing vascular damage by regulating atheroprotective anti-inflammatory transcription factors.

In conclusion, we here show that indirect metabolic and direct molecular anti-inflammatory effects of AT1R deficiency are, at least in part, mediated by PPAR $\gamma$ regulation. Interlocking regulation of PPAR $\gamma$ and the AT1R might explain why the use of Ang II blockers is associated with the improvement of anti-inflammation and glucose and lipid metabolism even without intrinsic PPAR $\gamma$ agonism. However, the role of the RAAS in mediating vascular protective effects by PPAR $\gamma$ regulation is presently not fully understood, particular not in the metabolic conditions of hypercholesterolemia and type 2 diabetes. Moreover, whether combined AT1R blockage and PPAR $\gamma$ activation results in a synergistic clinical benefit remains an unsolved question.

However, the role of an AT1R-PPAR $\gamma$ crosstalk favorably affecting metabolic, genetic and oxidative parameters promoting anti-atherogenesis is a promising area for future research. The prospect of this study relies on further mechanistic analysis of the vascular effects of receptor interactions, and the identification of modulators thereby enhancing the use of atheroprotective modifications in cardiovascular disease.

\section{Acknowledgments}

Vedat Tiyerili MD and Ulrich M. Becher MD -contributed equally.

Vedat Tiyerili (O-109.0042) and Ulrich M. Becher (O-100.90040) were supported by BONFOR, University of Bonn, Germany.

\section{Conflict of interest}

The authors declare no conflict of interest.

\section{References}

1. Nickenig G, Harrison DG. The AT(1)-type angiotensin receptor in oxidative stress and atherogenesis: part I: oxidative stress and atherogenesis. Circulation 2002; 105: 393-6.

2. Nickenig G, Baumer AT, Temur Y, Kebben D, Jockenhovel F, Bohm M. Statin-sensitive dysregulated AT1 receptor function and density in hypercholesterolemic men. Circulation 1999; 100: 2131-4.

3. Warnholtz A, Nickenig G, Schulz E, et al. Increased $\mathrm{NADH}$-oxidase-mediated superoxide production in the early stages of atherosclerosis: evidence for involvement of the renin-angiotensin system. Circulation 1999; 99: 2027-33. 
4. Wassmann S, Nickenig G. Pathophysiological regulation of the AT1-receptor and implications for vascular disease. J Hypertens Suppl 2006; 24: S15-21.

5. Turnbull F. Blood Pressure Lowering Treatment Trialists' Collaboration. Effects of different blood-pressure-lowering regimens on major cardiovascular events: results of prospectively-designed overviews of randomised trials. Lancet 2003; 362: 1527-35.

6. Fujisaka S, Usui I, Kanatani Y, et al. Telmisartan improves insulin resistance and modulates adipose tissue macrophage polarization in high-fat-fed mice. Endocrinology 2011; 152: 1789-99.

7. Gerstein HC, Yusuf S, Mann JFE, et al. Effects of ramipril on cardiovascular and microvascular outcomes in people with diabetes mellitus: results of the HOPE study and MICRO-HOPE substudy. Heart Outcomes Prevention Evaluation Study Investigators. Lancet 2000; 355: 253-9.

8. Lindholm LH, Ibsen H, Borch-Johnsen K, et al. Risk of new-onset diabetes in the losartan intervention for endpoint reduction in hypertension study. J Hypertens 2002; 20: 1879-86.

9. Andraws R, Brown DL. Effect of inhibition of the renin-angiotensin system on development of type 2 diabetes mellitus (meta-analysis of randomized trials). Am J Cardiol 2007; 99: 1006-12.

10. Yamana A, Arita M, Furuta M, Shimajiri Y, Sanke T. The angiotensin II receptor blocker telmisartan improves insulin resistance and has beneficial effects in hypertensive patients with type 2 diabetes and poor glycemic control. Diabetes Res Clin Pract 2008; 82: 127-31.

11. Benson SC, Pershadsingh $\mathrm{HA}, \mathrm{Ho} \mathrm{Cl}$, et al. Identification of telmisartan as a unique angiotensin II receptor antagonist with selective PPARgamma-modulating activity. Hypertension 2004; 43: 993-1002.

12. Schupp M, Janke J, Clasen R, Unger T, Kintscher U. Angiotensin type 1 receptor blockers induce peroxisome proliferator-activated receptor-gamma activity. Circulation 2004; 109: 2054-7.

13. Duan SZ, Usher MG, Mortensen RM. Peroxisome proliferator-activated receptor-gamma-mediated effects in the vasculature. Circ Res 2008; 102: 283-94.

14. Mieczkowska J, Mosiewicz K, Barud W, Kwaśniewski A Changes in the activity of connective tissue matrix enzymes in the metabolic syndrome. Arch Med Sci 2011; 7: 634-41.

15. Tiyerili V, Becher UM, Aksoy A, et al. AT1-receptor-deficiency induced atheroprotection in diabetic mice is partially mediated via PPARgamma. Cardiovasc Diabetol 2013; 12: 30

16. Chinetti G, Fruchart JC, Staels B. Peroxisome proliferator-activated receptors (PPARs): nuclear receptors at the crossroads between lipid metabolism and inflammation. Inflamm Res 2000; 49: 497-505.

17. Ertek S, Cicero A. Impact of physical activity on inflammation: effects on cardiovascular disease risk and other inflammatory conditions. Arch Med Sci 2012; 8: 794-804

18. Gersh BJ, Sliwa K, Mayosi BM, Yusuf S. The epidemic of cardiovascular disease in the developing world: global implications. Eur Heart J 2010; 31: 642-8.

19. Ross R. Atherosclerosis: an inflammatory disease. N Engl J Med 1999; 340: 115-26.

20. Harrison D, Griendling KK, Landmesser U, Hornig B, Drexler $\mathrm{H}$. Role of oxidative stress in atherosclerosis. Am J Cardiol 2003; 91: 7A-11A.

21. Libby P, Ridker PM, Maseri A. Inflammation and atherosclerosis. Circulation 2002; 105: 1135-43.
22. Burchardt P, Zurawski J, Zuchowski B, et al. Low-density lipoprotein, its susceptibility to oxidation and the role of lipoprotein-associated phospholipase A2 and carboxyl ester lipase lipases in atherosclerotic plaque formation. Arch Med Sci 2013; 9: 151-8.

23. Wassmann S, Nickenig G. The role of the AT1 receptor in the cardiovascular continuum. Eur Heart J Suppl 2004; 6 (Suppl H): H3-9.

24. Mendelsohn ME, Karas RH. Molecular and cellular basis of cardiovascular gender differences. Science 2005; 308: 1583-7.

25. Tiyerili V, Müller CF, Fung S, Panek D, Nickenig G, Becher UM. Estrogen improves vascular function via peroxisome-proliferator-activated-receptor-gamma. J Mol Cell Cardiol 2012; 53: 268-76.

26. Clasen R, Schupp M, Foryst-Ludwig A, et al. PPARgamma-activating angiotensin type-1 receptor blockers induce adiponectin. Hypertension 2005; 46: 137-43.

27. Takeda K, Ichiki T, Tokunou T, et al. Peroxisome proliferator-activated receptor gamma activators downregulate angiotensin II type 1 receptor in vascular smooth muscle cells. Circulation 2000; 102: 1834-9.

28. Ji Y, Liu J, Wang Z, Lui N. Angiotensin II induces inflammatory response partly via Toll-like receptor 4-dependent signaling pathway in vascular smooth muscle cells. Cell Physiol Biochem 2009; 23: 265-76.

29. Luther JM, Gainer JV, Murphey LJ, et al. Angiotensin II induces interleukin-6 in humans through a mineralocorticoid receptor-dependent mechanism. Hypertension 2006; 48: 1050-7.

30. Tak PP, Firestein GS. NF-kappaB: a key role in inflammatory diseases. J Clin Invest 2001; 107: 7-11.

31. Remels AHV, Langen RCJ, Gosker HR, et al. PPARgamma inhibits NF-kappaB-dependent transcriptional activation in skeletal muscle. Am J Physiol Endocrinol Metab 2009; 297: E174-83.

32. Duan SZ, Usher MG, Mortensen RM. Peroxisome proliferator-activated receptor-gamma-mediated effects in the vasculature. Circ Res 2008; 102: 283-94.

33. Jung UJ, Torrejon C, Chang CL, Hamai H, Worgall TS, Deckelbaum RJ. Fatty acids regulate endothelial lipase and inflammatory markers in macrophages and in mouse aorta: a role for PPARgamma. Arterioscler Thromb Vasc Biol 2012; 32: 2929-37.

34. Lin Q, Jia L. Sun Y. A pilot study of circulating PPAR-gamma receptor protein in elderly patients with atrial fibrillation. Arch Med Sci 2012; 8: 471-6.

35. Brenner BM, Cooper ME, de Zeeuw D, et al.; RENAAL Study Investigators. Effects of losartan on renal and cardiovascular outcomes in patients with type 2 diabetes and nephropathy. N Engl J Med 2001; 345: 861-9.

36. Yusuf S, Sleight P, Pogue J, Bosch J, Davies R, Dagenais G. Effects of an angiotensin-converting-enzyme inhibitor, ramipril, on cardiovascular events in high-risk patients. The Heart Outcomes Prevention Evaluation Study Investigators. N Engl J Med 2000; 342: 145-53.

37. Yusuf S, Teo KK, Pogue J, et al. Telmisartan, ramipril, or both in patients at high risk for vascular events. N Engl J Med 2008; 358: 1547-59. 